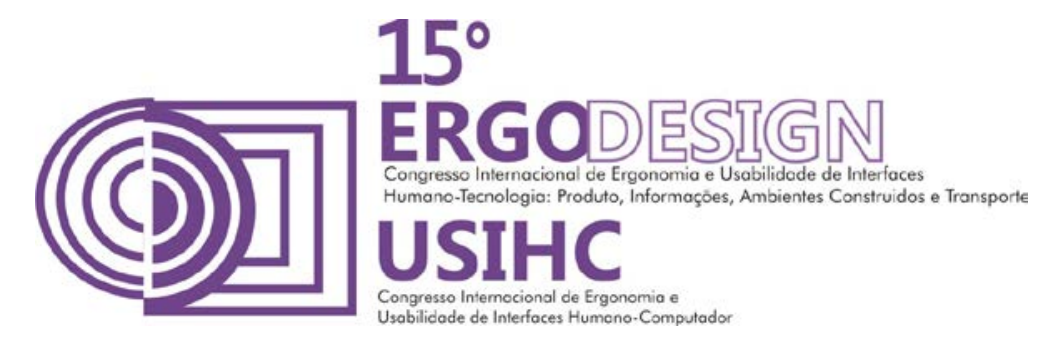

\title{
A OBSERVAÇÃO DO COMPORTAMENTO DO USUÁRIO PARA O WAYFINDING NO AMBIENTE CONSTRUÍDO
}

\section{THE USER BEHAVIOR OBSERVATION FOR WAYFINDING IN THE BUILT ENVIRONMENT}

\author{
RANGEL, Márcia Moreira (1); \\ Mont'Alvão, Cláudia (2) \\ (1) IF Sudeste MG/ Câmpus Juiz de Fora, Mestre em Design \\ e-mail:marcia.rangel@ifsudestemg.edu.br \\ (2) Pontifícia Universidade Católica do Rio de Janeiro, Doutora em Engenharia de Transportes \\ e-mail:cmontalvao@puc-rio.br
}

\begin{abstract}
RESUMO
Este estudo apresenta uma sistematização da observação do comportamento do usuário perante a tarefa de se deslocar no ambiente construído. A estrutura da observação se pauta no "o quê" e no "como" observar. Apresenta revisão bibliográfica acerca do comportamento do usuário no wayfinding como base para a categorização de comportamentos observáveis. Para a observação/ registro de comportamento propõe-se a técnica do mapeamento do comportamento espacial. Tal técnica configura a maneira de observar o comportamento do usuário durante sua navegação e catalogar dados sobre o desempenho da informação do ambiente.

Palavras-chave: Ergonomia do ambiente construídot; wayfinding, usuário
\end{abstract}

\begin{abstract}
This study introduces a systematic overview of user behavior observation when confronted with the user's task of moving around in a built environment. The observation framework is based on "what" and "how" to observe. It includes a literature review about user wayfinding behavior as the basis for the categorization of observable behaviors. Spatial behavior mapping technique is proposed for behavior observation/registration. This technique sets the way to observe user behavior during his/her navigation and to log data on the performance of environmental information.
\end{abstract}

Keywords: Ergonomics of the built environment; wayfinding, user 


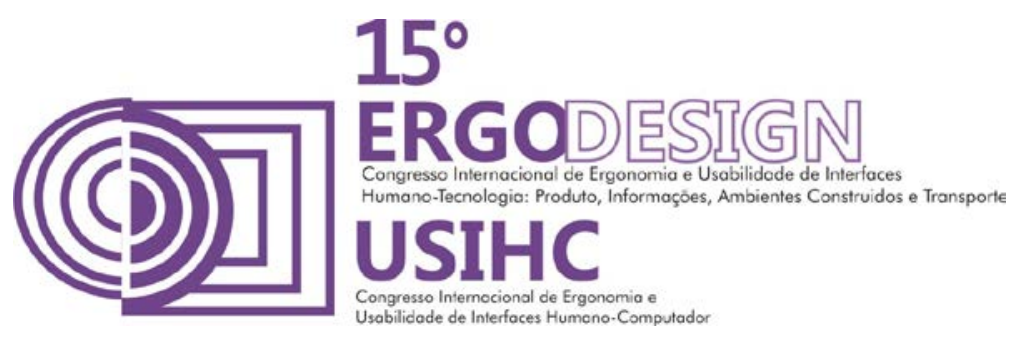

\section{INTRODUÇÃO}

A pesquisa em Ergonomia visa estudar o homem e suas habilidades, a tarefa a ser realizada e o sistema no qual essa ocorre, sempre convergindo os métodos investigativos para a captação de dados no decorrer da tarefa. A tecnologia humano-sistema, é apontada por Hendrick (1993 apud MORAES.ORG. 2001), como a única tecnologia pertinente à ergonomia.

A ergonomia moderna, que se caracteriza por ser centrada no indivíduo, indica ser este o controlador do sistema e capaz de alterá-lo conforme suas habilidades e vontade. Dessa forma, para sua efetividade, o sistema deve ser projetado sob o ponto de vista do usuário. Tal enfoque considera a interação humano/sistema como "controlada e conduzida" pelo usuário, contudo, visa um ambiente de interação adaptado às habilidades e necessidades desse usuário (MORAES E MONT'ALVÃO, 2003, p.27).

$\mathrm{Na}$ realização de sua pesquisa, a ergonomia se utiliza de ferramentas metodológicas para abarcar conhecimentos acerca de "capacidades, limites e outras características do desempenho humano, à medida que elas se relacionam com o projeto de interfaces e outros componentes do sistema" (MORAES.ORG, 2001, p.9).

O ambiente construído configura-se em um dos sistemas abordados pela pesquisa ergonômica, e suas ferramentas metodológicas visam compreender e identificar os elementos envolvidos na interação humano/ambiente. Entendendo-se aqui o ambiente construído como um cenário social de naturezas e interfaces diversas, que propiciam múltiplas interações aos usuários.

Dentre as interfaces humano/ambiente, o deslocamento de um ponto ao outro para realizar determinada atividade é uma tarefa, que envolve o processamento da informação advinda dos diversos elementos que compõe o ambiente, a decisão da melhor rota, o monitoramento da rota para confirmar o caminho certo e o reconhecimento do destino. São questões cognitivas que abarcam a orientação espacial no ambiente construído, e trazem custos humanos quando o usuário, ao acionar seu mapa mental do ambiente, não consegue cumprir todas as etapas da tarefa de chegar/reconhecer o destino, a partir das informações captadas.

Com enfoque no desempenho do usuário frente à sua tarefa de deslocar-se em determinada rota para realizar sua atividade, este artigo apresenta questões pertinentes à coleta de dados acerca da observação do comportamento espacial do usuário no ambiente construído. A abordagem é pautada nos fundamentos do wayfinding, uma vez que visa captar as soluções para navegação dos usuários em determinado ambiente, em seu processo de orientação espacial.

O artigo primeiramente a aborda o usuário e seu comportamento elencados ao wayfinding. Depois, traz questões acerca da observação/registros de comportamento e apresenta uma sistemática para essa observação. Apresenta, ainda, as planilhas de observação com comportamentos típicos a serem observados, levantados da literatura.

Cumpre asseverar que o estudo tem delineamento teórico/propositivo, pois é uma proposta ainda a ser aplicada. Contudo, apresenta conteúdo e relevância propícios à discussão. 


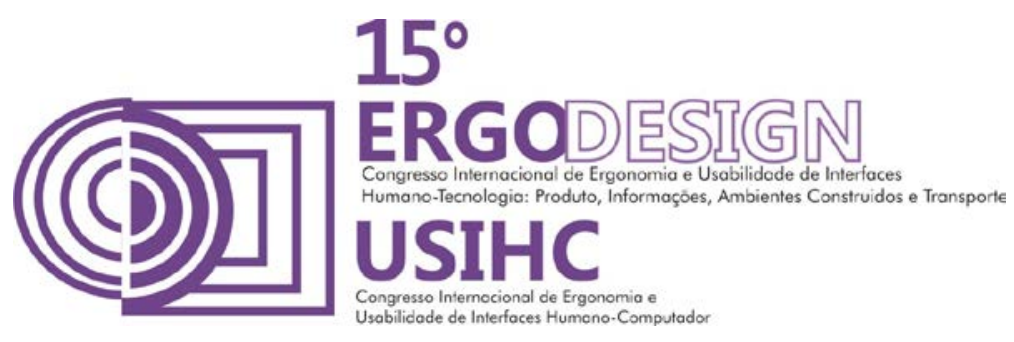

\section{WAYFINDING E O USUÁRIO}

Estar orientado é saber onde está e para onde ir sem a ajuda de terceiros, esse é o princípio da autonomia na navegação. É uma necessidade do ser humano que remonta ao seu instinto de sobrevivência. Na sociedade contemporânea a necessidade de orientação está elencada à segurança no ambiente, a não perder tempo e dinheiro, evitar frustração, estresse e crises de ansiedade. Essas são questões importantes para o indivíduo, portanto devem ser de interesse daqueles que administram e os que desenvolvem projetos para o ambiente construído. (ARTHUR E PASSINI, 1992; CARPMAN, 2000; CARPMAN E GRANT, 2008; RIBEIRO, 2009).

A interface Ergonomia do Ambiente Construído (EAC)/wayfinding está na relação do ambiente construído e o comportamento do usuário, uma vez ser, segundo Ribeiro (2009), do interesse da EAC aperfeiçoar os espaços no sentido de torna-los cada vez mais adequados para a promoção do bem-estar e da segurança de quem neles interage. Esses são aspectos relevantes para o wayfinding.

As contínuas transformações sociais plasmam ambientes com arranjo espacial complexo que impede e/ou limita a apreensão do espaço, dificultando ao usuário localizar-se e planejar seu deslocamento (CARPMAN, 2000; RIBEIRO, 2009). Ribeiro (2009) ressalta que as diversas pesquisas que apontam a desorientação como causa de insatisfação do usuário, revelam diversos problemas do ambiente em relação a sinalizar e a orientar o usuário. É, portanto, nesta lacuna entre o ambiente construído e o usuário que o wayfiniding se situa.

O wayfinding aborda a relação sujeito/ambiente, considerando que estão envolvidos aspectos relativos a ambos. Quanto ao ser humano serão consideradas suas habilidades individuais, que irão caracterizar sua percepção e cognição frente ao ambiente construído em sua tarefa de deslocar-se. O ambiente construído será o provedor das informações para a orientação espacial.

O wayfinding possui dois vieses complementares de abordagem. Para Arthur e Passini (1992) é um processo que se desenvolve gradualmente da relação sujeito/ambiente. Esse processo que envolve o processamento da informação, a tomada de decisão e a execução da decisão, tem como princípio norteador a relação dinâmica (de troca) entre o indivíduo e o ambiente. Para Carpman e Grant (2002) é um sistema conformado por três subsistemas comportamento + design + operacional, cujas ações desenvolvidas irão conduzir o indivíduo a saber onde está, encontrar um caminho para o seu destino e retornar ao local de onde partiu.

$\mathrm{Na}$ relação sujeito/ambiente, sob a perspectiva do sujeito-usuário, "encontrar o caminho" é uma ação que deveria ser intuitiva e com o menor esforço cognitivo e interpretativo. Mediante essa assertiva, cabe ao ambiente fornecer as informações necessárias à orientabilidade dos indivíduos contemplando suas habilidades, ou mesmo, suas restrições (BINS ELY, IN MORAES.ORG. 2004). No processo de orientação espacial a relação sujeito/ambiente pode ser melhor compreendida a partir da modelagem do processamento da informação apresentada na figura 1. Essa modelagem, que envolve questões perceptivas e cognitivas, foi desenvolvida por Rangel (2011) a partir de estudos realizados por diversos autores. 

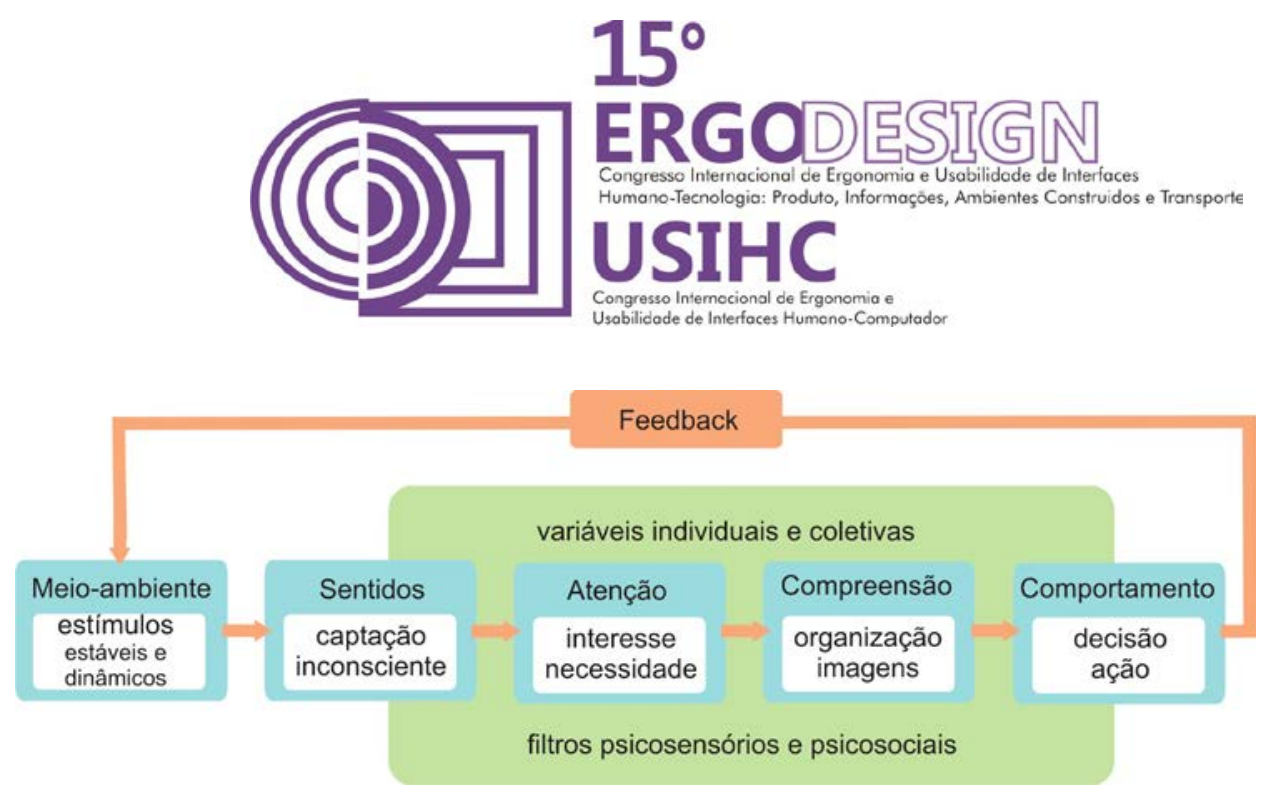

Figura 1 - Modelagem do processo perceptivo na interação humano-ambiente Fonte - Rangel, 2011, p.73

A tomada de decisão decorre do desenvolvimento de um plano de ação derivado do processamento da informação, em que entra em jogo a percepção dos elementos do ambiente, captadas pelos sentidos. A cognição decorre da atenção e da compreensão das informações captadas. Esses dois processos dependem das características próprias do sujeito-usuário e de suas habilidades individuais para interpretar a informação.

A execução da decisão é um processo que demanda uma ação observável, é um comportamento que pressupõe o movimento do corpo em busca do destino.

A orientação, portanto, ocorre a partir de uma interação dialogada - passo-a-passo, nó-a-nó, na qual surgem contínuas perguntas para o ambiente e respostas do indivíduo, conformadas nas ações interpretadas. Dessa forma, o comportamento espacial configura-se a partir de: 1) Habilidades e características próprias, que são as habilidades intrínsecas ao indivíduo; 2) Reação ao ambiente, que são as ações derivadas da interpretação dos estímulos de orientação e das tomadas de decisões.

\section{COMPORTAMENTO DE WAYFINDING}

O ser humano possui mecanismos naturais de navegação, decorrentes de um longo processo evolutivo, no qual suas habilidades para encontrar um local estão definitivamente ligadas ao seu instinto de sobrevivência. O comportamento espacial, dessa forma, é adaptável, pois nossos mecanismos de investigação e de fuga foram moldados, ao longo de nossa evolução, de maneira relativamente independente do conhecimento geométrico exato do ambiente. Podemos formatar um comportamento espacial a partir de modelos mentais que servirão como matrizes adaptadas para cada espaço a ser navegado (SEBEOK, 2001; ZINGALE, 2010).

A partir dessa teoria podemos entender porque as pessoas tendem a encontrar um destino, mesmo em ambientes desconhecidos e com pouca informação para sua orientação. Primeiramente, os mecanismos interiores de busca irão investigar o ambiente para encontrar os meios necessários para se situar e se deslocar, e ao se sentir perdido, os mecanismos de defesa serão acionados colocando em alerta todos os canais sensórios para captar informações para a navegação.

Isso também demonstra que o indivíduo tem predisposição a encontrar seu destino e busca por vários meios realizar sua tarefa de deslocar-se. O fato de perder-se, de demorar a encontrar o destino, de ter de pedir auxílio a outras pessoas é gerador de estresse, pois, se não impede, 


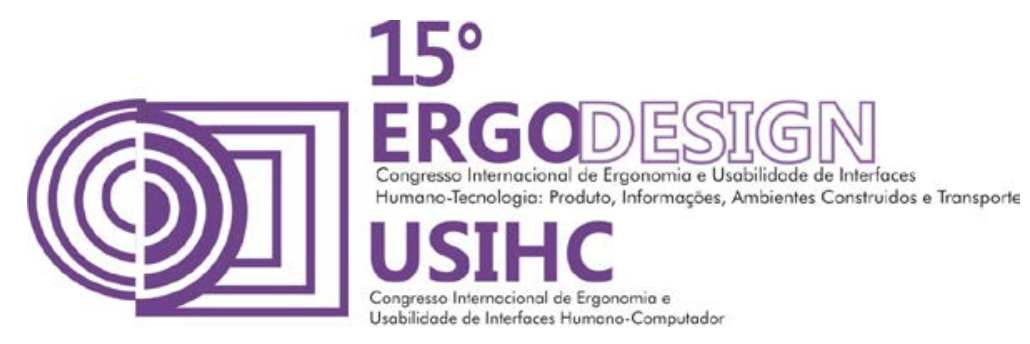

limita o ser humano a navegar com autonomia, seguindo seus próprios instintos e habilidades para captar a informação do ambiente.

Zingale (2010) pontua que a orientação, a exploração e a navegação, configuram-se em três modalidades de comportamento espacial. Essas três modalidades são pertinentes às quatro fases de wayfinding - orientação, decisão da rota, monitoramento da rota e reconhecimento do destino - apontadas por Atkins et. al. (2008). A compilação e interpretação dos estudos dos autores são apresentadas a seguir.

O comportamento de orientação decorre da pergunta "onde estou?". O indivíduo precisa ter consciência de sua localização geográfica no espaço e ter conhecimento de sua posição dentro do mesmo. Visa interpretar o espaço e seus eventos a partir de conexões de reciprocidade, ou seja, estabelecer relações, dimensões, orientação e posicionamentos entre ele e o ambiente e os elementos entre si.

A pergunta elencada ao comportamento de exploração é "para onde vou?". O comportamento é investigativo. Visa compor o modelo mental do espaço real a partir de similaridades com mapas mentais padrões. É também interpretativo e de reconhecimento das qualidades sensoriais da configuração do ambiente, seus objetos e eventos, e ainda é associativo, uma vez que o indivíduo busca semelhanças para associá-las a ideias e "imagens evocativas".

A orientação e a exploração irão propiciar ao indivíduo decidir a rota para chegar ao seu destino.

A Navegação responde à seguinte questão: "como prossigo?". É o movimento em direção ao destino. É a competência para se deslocar e utilizar o mapa mental. Para navegar é necessário ao sujeito-usuário determinar direções, calcular a distância do objetivo, ser capaz de identificar os nós, de reconhecer marcos referenciais, etc. A navegação envolve o deslocamento e o monitoramento da rota para não perder a noção de lugar (onde está) em nenhum ponto do trajeto. A orientação, portanto, é uma constante em todo o processo.

É interessante observar que o monitoramento abarca a memorização dos locais por onde passa, para ser capaz de refazer o percurso tanto em direção ao destino quanto para retornar ao local de partida, quantas vezes se fizer necessário, sem que haja problema de se perder ao longo do caminho. É necessário pensar a rota de forma sistemática e estabelecer claramente um início, pontos intermediários e o destino. As informações ao longo do caminho têm também o sentido de marcar estrategicamente determinados pontos, estabelecendo as referências que auxiliarão o individuo a se situar e compreender o caminho de ida e de volta.

O reconhecimento do destino configura-se no êxito de todo o processo que envolve as três modalidades de comportamento, seja indo ou retornando. Nesse processo o conhecimento da tarefa e o conhecimento dos locais para onde se dirigir são mais duas variáveis imprescindíveis a esse êxito.

Essas modalidades de comportamento são passíveis de observação quando delas se extraem ações comportamentais ou comportamentos observáveis passíveis de descrição e de categorização.

\section{OBSERVAÇÃO E REGISTRO DO COMPORTAMENTO}




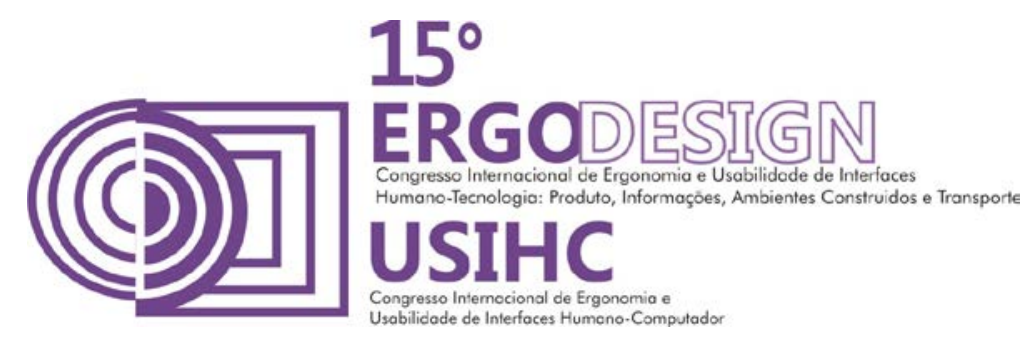

As pesquisas em ergonomia realizam de uma forma geral, duas modalidades de observação a observação assistemática e a observação sistemática. Embora não seja o único e nem o determinante instrumento de coleta de dados, a importância da observação é apontada por Moraes e Mont'Alvão (2003, p.7), quando explicitam ser esta uma fase determinante para a pesquisa, por ser a base que configura problemas e hipóteses, como também, é sustentação para os demais métodos e técnicas.

A observação sistemática é o enfoque desse estudo. Tal observação tem caráter estruturador, onde os propósitos - "o quê" e "como" observar - para se obter respostas acerca de questões da pesquisa, são definidos anteriormente. Utiliza usualmente como suporte, os dados preparados a partir da observação assistemática. Aqui, os dados coletados em pesquisa documental nas plantas arquitetônicas, são também apoio para a sistematização e o preparo dos documentos da observação.

Para a eficiência da observação sistemática é necessário (1) delimitar a área da realidade a ser observada; (2) indicar a população (o que ou quem), as circunstâncias (quando) e o local (onde) a ser observado; (3) preparar material de apoio à observação - planilhas de registro, fichas de entrevista, equipamentos de fotografia e filmagem etc. Esses são alguns pontos pertinentes e fundamentais à observação (MORAES E MONT'ALVÃO, 2003, p.39).

Os registros de comportamento estão elencados à observação sistemática, e compõe o estudo do comportamento do usuário frente à sua tarefa (MORAES E MONT'ALVÃO, 2003, p.39). Tal registro objetiva levantar e anotar os dados observados acerca das ações assumidas pelo usuário. Para Fagundes (2006, p.59), registrar os comportamentos é também importante na medida em que facilita "a análise posterior, dificultando a ação do esquecimento".

Fagundes (2006) explicita que para a observação, os comportamentos devem ser definidos para se eliminar possíveis contradições de interpretações. É necessário apresentar definições explícitas e completas, por meio de linguagem científica (objetiva, clara, exata, concisa e direta), e com denominações de rápida associação com o que está sendo designado. O resultado da observação deve apresentar somente o que foi percebido pelos sentidos, não devendo 0 observador acrescentar suas interpretações.

Para facilitar a observação do comportamento, Fagundes (2006) recomenda ao observador, antes de começar o registro, se ambiente à situação para que o sujeito não estranhe a sua presença. Além disso, deve se manter a uma distância razoável do observado em uma atitude neutra e discreta, e não interferir na situação, a não ser que a interferência seja objeto do estudo.

Além das questões supracitadas para a eficácia da observação, Fagundes (2006) entende ser importante para o registro comportamental a marcação do tempo de duração, e o esclarecimento da técnica de registro adotada.

Dos estudos apresentados por Fagundes (2006) e Danna e Matos (2006), destacamos duas modalidades de registro de comportamento: o registro cursivo e os registros categorizados. $\mathrm{O}$ registro cursivo trata de descrever os comportamentos sequencialmente, ou seja, na medida em que os fatos ocorrem (FAGUNDES, 2006). Para os registros categorizados, o observador utiliza categorias pré-definidas. As categorias emergem do conhecimento prévio do pesquisador e de seus autores (DANNA E MATOS, 2006). Isso implica, conforme apresentado acima, a definição do o quê observar. 


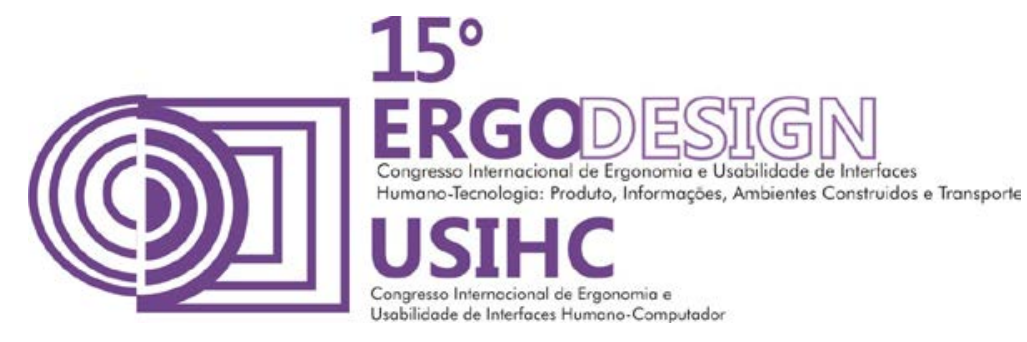

\subsection{O QUE OBSERVAR?}

No contexto desse estudo, o que observar, de maneira objetiva e sistematizada, abarca questões pertinentes ao comportamento espacial do usuário. O olhar volta-se para as ações comportamentais, frente à decisão da rota, o monitoramento da rota e o reconhecimento do destino.

A postura, a exploração visual, as tomadas de informações, as comunicações e os deslocamentos (MORAES E MONT'ALVÃO, 2003, pp. 39 e 40) são comportamentos observáveis relacionados aos comportamentos de orientação, de localização e de exploração (ZINGALE, 2010). É possível observar nesses comportamentos a situação de orientação, de indecisão e de desorientação do usuário, conforme apresentado na tabela 1.

Tabela 1 - Comportamentos espaciais observáveis

Fonte: a autora 


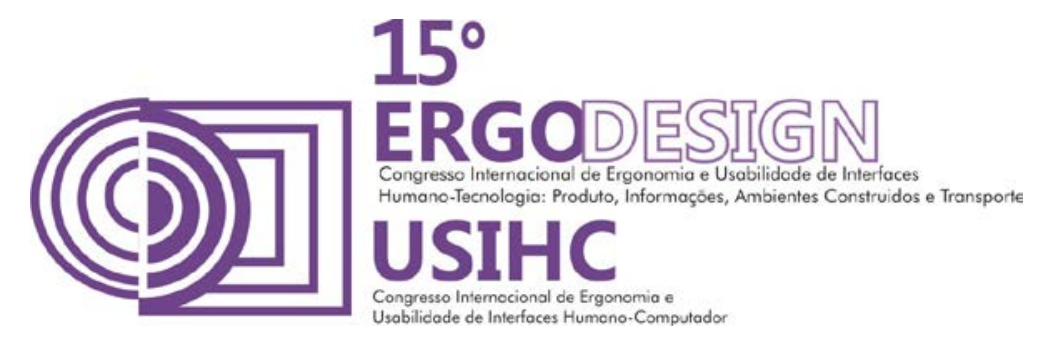

\begin{tabular}{|c|c|c|}
\hline CATEGORIA & $\begin{array}{l}\text { ORIENTAÇÃO } \\
\text { ESPACIAL }\end{array}$ & AÇŌES \\
\hline \multirow{3}{*}{$\begin{array}{l}\text { Andar- caminhar } \\
\text { em determinada } \\
\text { direção }\end{array}$} & Orientação & Deslocamento com decisão e autonomia. \\
\hline & Indecisão & Andar/parar/ continuar ou seguir outra direção. \\
\hline & Desorientaçāo & $\begin{array}{l}\text { Andar/parar/mudar de direção/ retornar/ } \\
\text { empreender nova direção; ajuda de terceiros. }\end{array}$ \\
\hline \multirow{3}{*}{$\begin{array}{l}\text { Olhar - movimento } \\
\text { da cabeça e dos } \\
\text { olhos para buscar } \\
\text { informação na } \\
\text { sinalização, no } \\
\text { ambiente ou com } \\
\text { terceiros. }\end{array}$} & Orientação & $\begin{array}{l}\text { Cabeça voltada para a direção a seguir, olhar a } \\
\text { informação à distância e/ou enquanto caminha e } \\
\text { identificar a continuidade da rota. }\end{array}$ \\
\hline & Indecisão & $\begin{array}{l}\text { Movimentos da cabeça em outras direções, com } \\
\text { movimentos de varredura dos olhos; direcionar o } \\
\text { olhar em direção a determinado objeto para } \\
\text { discriminação e identificação; mirar uma direção } \\
\text { e seguir. }\end{array}$ \\
\hline & Desorientação & $\begin{array}{l}\text { Movimentos da cabeça em várias direções (para } \\
\text { frente, para trás e para os lados) com movimen- } \\
\text { tos de varredura dos olhos; o olhar tramita de um } \\
\text { objeto a outro para discriminação e identificação; } \\
\text { os procuram por outras pessoas. }\end{array}$ \\
\hline \multirow{3}{*}{ Parar } & Orientação & $\begin{array}{l}\text { Parar em locais de descanso, banheiro, lancho- } \\
\text { nete e retornar para a continuidade do caminho; }\end{array}$ \\
\hline & Indecisão & Parar para se localizar \\
\hline & Desorientação & $\begin{array}{l}\text { Parar/seguir/retornar/parar e pegar informações } \\
\text { com terceiros. }\end{array}$ \\
\hline \multirow{3}{*}{$\begin{array}{l}\text { Expressões } \\
\text { faciais e verbais }\end{array}$} & Orientação & $\begin{array}{l}\text { Seguem em direção ao destino sem sinais faciais } \\
\text { ou verbais de dúvida e descontentamento com o } \\
\text { ambiente e com o seu deslocamento; }\end{array}$ \\
\hline & Indecisão & $\begin{array}{l}\text { Expressões de certa preocupação; olhar tenso, } \\
\text { morder os lábios; parar as mãos no rosto; } \\
\text { verbalizar a dúvida; }\end{array}$ \\
\hline & Desorientação & $\begin{array}{l}\text { Expressão bastante tensa; por as mãos na } \\
\text { cabeça e cabelos repetidamente; falar mais } \\
\text { alterado; reclamar; estressar. }\end{array}$ \\
\hline
\end{tabular}

Conforme apresentado na tabela 1, os comportamentos são categorizados de acordo com os estudos de Moraes e Mont'Alvão (2003), Ribeiro (2004) e Rangel (2011). São quatro (04) categorias, cujas ações são pertinentes a três situações elencadas à orientação espacial. Então, as categorias são (1) andar; (2) olhar; (3) parar e (4) expressões faciais e verbais durante as situações de orientação, indecisão e desorientação nos deslocamentos,

A partir do levantamento e da categorização do que observar, e após o mapeamento do ambiente no qual são levantados os setores/destino, as rotas dos usuários referentes às tarefas pesquisadas, os nós, marcos referenciais e a rota da sinalização pertinente aos deslocamentos, é necessário apontar como a observação deve acontecer. A técnica da observação sistemática do comportamento do usuário é apresentada a seguir. 


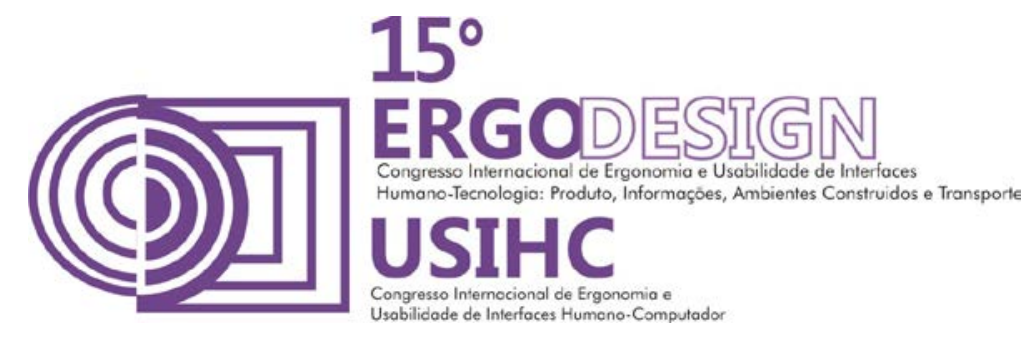

\subsection{COMO OBSERVAR}

A observação do comportamento do usuário utiliza técnica para o registro comportamental. Tal registro deve seguir a sequencia dos fatos, para registrar as ações categorizadas, portanto, há uma aproximação das duas modalidades propostas por Fagundes (2006) e Danna e Matos (2006).

Em um levantamento prévio com as técnicas dos autores Bins Ely et al. (2002), Atkins (2008), Ribeiro (2004), Baptista (2011) relativas a tal registro, foi verificada também certa aproximação entre as mesmas. As variações mais significativas para esta pesquisa versam sobre: (1) maior ou menor controle do tempo de registro; (2) maior ou menor aproximação do pesquisador durante o preparo do registro; (3) maior ou menor aproximação do pesquisador ao usuário durante o registro.

Para este estudo, a técnica proposta advém de adaptação a partir dos estudos dos autores pesquisados, sendo denominada de mapeamento do comportamento espacial. Nesta técnica a observação abarca as ações dos usuários em interação com a informação do ambiente, durante o seu deslocamento. O pesquisador ao preparar esta observação/ registros de comportamento, define:

(1) a rota de observação;

(2) delimita na planta baixa arquitetônica o trajeto, os nós, o suporte informacional durante o caminho, sobretudo os marcos referenciais;

(3) categoriza os comportamentos observáveis.

O usuário será definido conforme perfil previamente delineado pelo pesquisador e em conformidade com a tarefa. Nesta proposta, o pesquisador escolhe o usuário randomicamente no ambiente, de acordo com as características pré-estabelecidas.

Durante a observação, o pesquisador busca se manter neutro o suficiente para não ser notado. Observa a certa distância o comportamento do usuário e registra as ações observáveis categorizadas. Ao final, o usuário é convidado a fazer um breve relato sobre as facilidades e dificuldades do seu deslocamento. Essa medida visa esclarecer possíveis dúvidas na observação.

Os dados são registrados em planilha previamente preparada (Figuras 2 e 3), fotografias e/ou vídeos. 

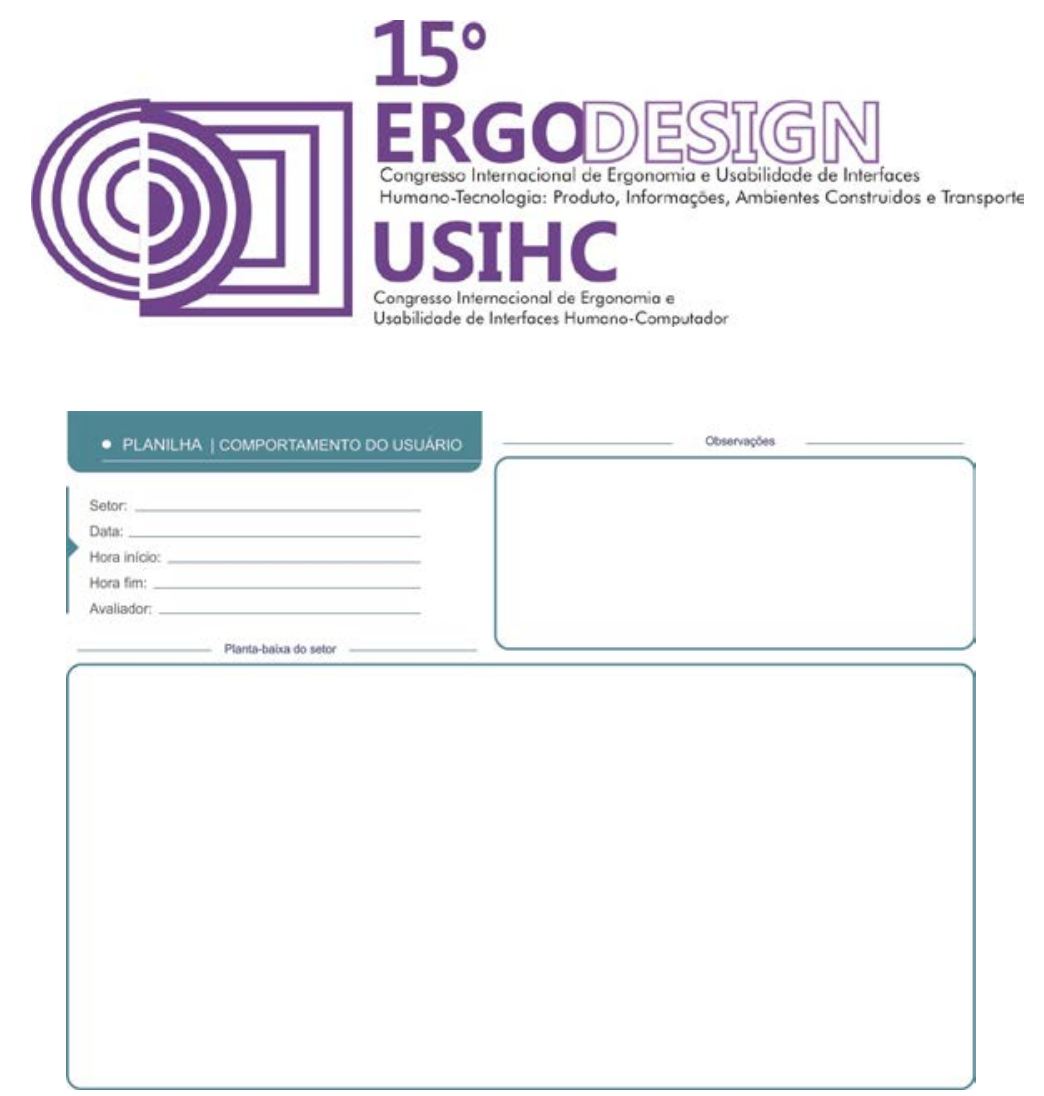

Figura 2 - Planilha de registro do comportamento do usuário (página 1) Fonte: a autora

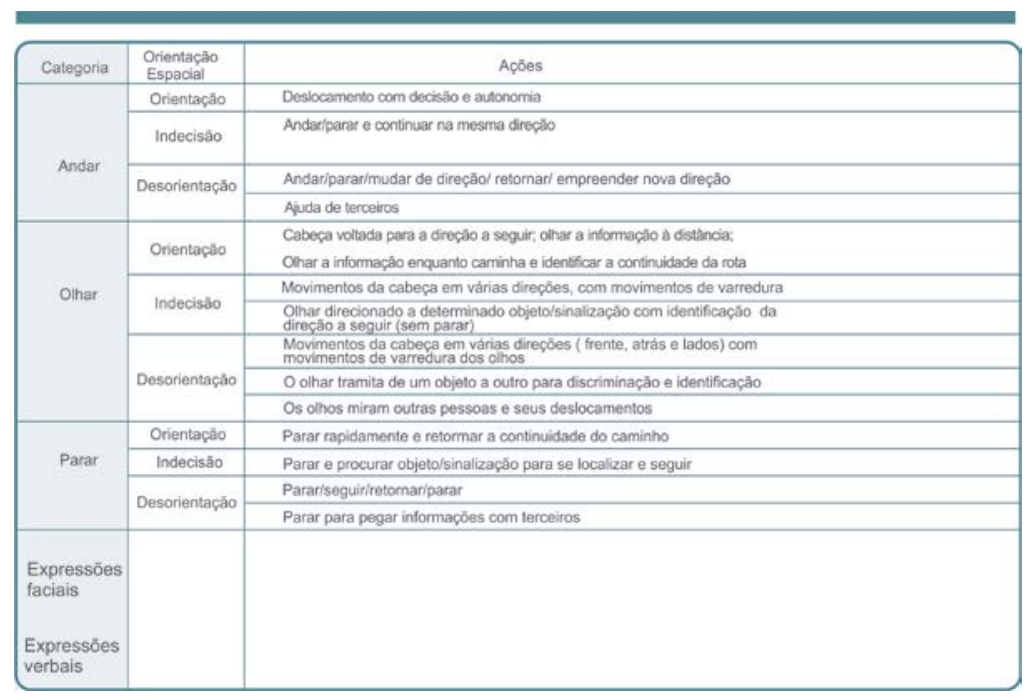

Figura 3 - Planilha de registro do comportamento do usuário (página 2) Fonte: a autora

$\mathrm{Na}$ planilha constam dados acerca do setor, da tarefa; da data, hora de início e hora do fim da avaliação, e o nome do avaliador. Ainda possui campo para a planta baixa ou plantas baixas, abarcando todas as circulações possíveis para o desenvolvimento da tarefa. O avaliador fará marcações com linhas para apontar as rotas dos usuários, e marcações com numerais dos pontos pré-estabelecidos como importantes para registrar os comportamentos. 


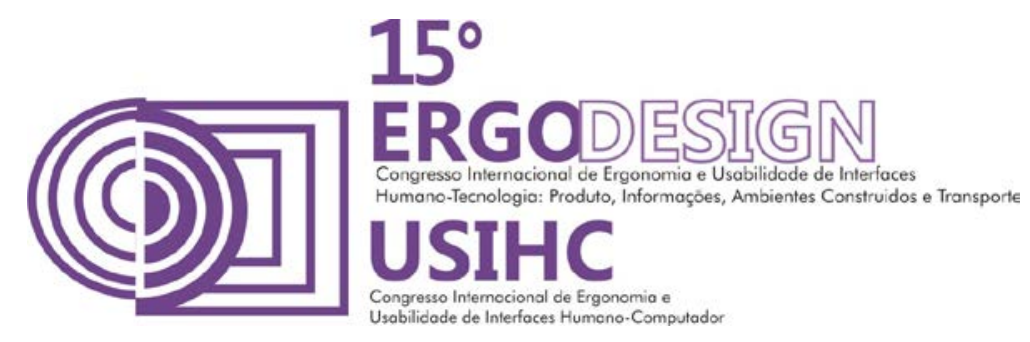

Os comportamentos previamente categorizados são registrados nas rotas e nos pontos prédeterminados na planta baixa. Como os comportamentos são complexos e possuem dados de imprevisibilidade, são considerados na planilha campos para pontos não previstos e que se apresentem relevantes na observação.

\subsection{OS RESULTADOS}

Os resultados a partir do cruzamento das variáveis: comportamento (andar/ olhar/ parar/ expressões) x situação (orientação/ indecisão/ desorientação) x local ocorrido, poderão apresentar dados quantitativos e qualitativos acerca da informação do ambiente construído na orientação espacial do usuário.

A tabulação irá evidenciar não só os locais no ambiente que apresentam falhas na informação layout e/ou sinalização, como também aqueles em que a informação está melhor configurada. É possível verificar dentre os observados, o número de usuários que se encontram orientados, indecisos ou desorientados em cada ponto. Além disso, podem indicar, por meio das expressões verbais, a satisfação/insatisfação dos observados com o ambiente.

Os dados levantados são relevantes para mensurar a visibilidade do ambiente nas rotas observadas, sendo incorporados ao corpus de dados relativos à observação do ambiente construído, para a aplicação da técnica do índice de visibilidade (VI). O índice de visibilidade (VI) é uma técnica que quantifica a visibilidade do ambiente. Foi desenvolvida por Braaksma e Cook (1980) para aferir o grau de visibilidade do ambiente de aeroportos. Lam et. al. (2002) e Ribeiro (2004 e 2009) utilizaram o VI para quantificar a visibilidade de aeroportos. Rangel (2011) a utilizou no estudo de um hospital.

O VI avalia o layout e a sinalização do ambiente, por meio do cálculo matemático da propriedade de visibilidade desses elementos alocados na rota dos usuários. A visibilidade é calculada ponto a ponto, e a soma da visibilidade dos pontos indica o grau de visibilidade do ambiente.

Os dados levantados com o registro do comportamento do usuário são a base para ratificar os nós pertinentes à rota pesquisada (FIGURA 4), e para desenvolver o gráfico linear com as linhas de visão (FIGURA 5). Tais linhas mostram se existe visão (direta ou indireta) de um ponto ao outro da rota. A visão direta é propiciada pelos elementos da arquitetura e pelo layout do espaço, e a indireta advém de informações adicionais tais como a sinalização.

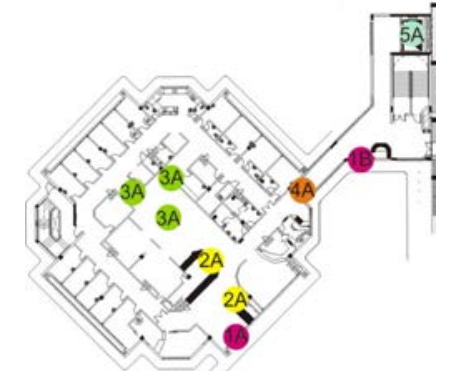

Figura 4 - Localização dos nós na planta baixa Fonte: Rangel, 2011, p.159

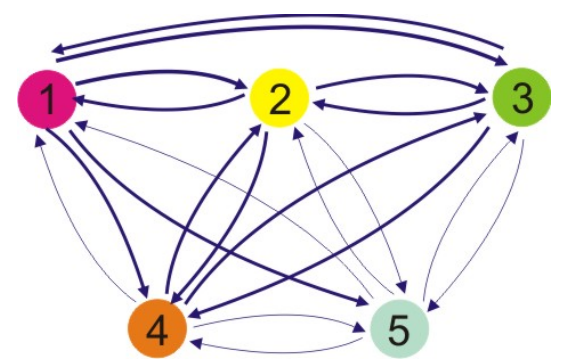

Figura 5 - matriz linear com as linhas de visão Fonte: Rangel, 2011, p.159 


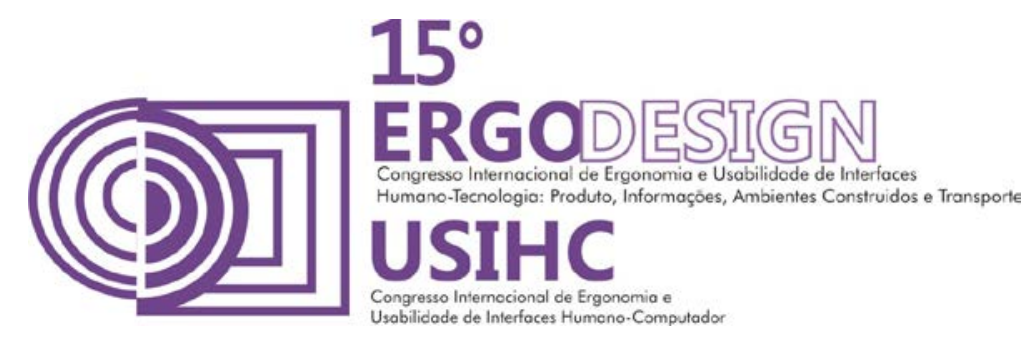

As linhas de visão estabelecem a rede de conexões com a visibilidade entre os nós. Para analisar com maior clareza tal rede de conexões, essa é desdobrada em uma matriz binária quadrática - matriz de visibilidade. Para o nó percebido a partir de outro ponto o valor registrado é 1. Caso contrário o valor é 0 (BRAAKSMA E COOK, 1980).

O VI induz a análise mais criteriosa dos dados levantados nos registros de comportamento. Visa verificar o desempenho dos deslocamentos e da informação ponto a ponto.

\section{CONSIDERAÇÕES}

O comportamento espacial decorre de mecanismos naturais, contudo, emerge da consciência dos seus movimentos e da atenção aos detalhes do ambiente. Durante a navegação, o usuário reage, consciente ou inconscientemente, frente às facilidades e dificuldades para iniciar, continuar e concluir sua rota. Estas reações expansivas ou contidas são ações observáveis, que podem ser indicadoras de problemas de wayfinding.

Entendemos ser de grande importância ao projeto que envolve o wayfinding no ambiente construído, categorizar e mapear esse comportamento ponto a ponto no ambiente. Este estudo, portanto, visa contribuir com a pesquisa em ergonomia por apresentar os comportamentos passíveis de serem observados em ambientes diversificados e pertinentes a diversos perfis de usuários.

Conforme apresentado, a observação é a base para a compreensão da situação que envolve a tarefa pesquisada, como também, para o planejamento e desenvolvimento de outros métodos e técnicas. Ocorrem, dessa forma, que os dados coletados por meio dos registros de comportamento aqui apresentado, devam ser utilizados em outras técnicas, com destaque para o VI. Os resultados cruzados ofertarão, certamente, maior efetividade para a pesquisa.

\section{REFERÊNCIAS BIBLIOGRÁFICAS}

ARTHUR P, PASSINI, R. Wayfinding: people, signs, and architecture. New York: McGraw-Hill, Inc., 1992.

ATKINS, L.; HUR, M. B. \& YANG, F. Way-Finding: Entrance Areas in Health Care Facilities. Health Design\&Research. ARCH: 675-600, 2003 Available online 21 February, 2008.

BRAAKSMA, J.P; COOK, W.J. Human Orientation in transportation terminals. Journal of transportation engineering, 1980.106, 189-203.

BINS ELY, V. H. M. Ergonomia + Arquitetura: Buscando um melhor desempenho do ambiente físico. In MORAES, Anamaria; AMADO, Giuseppe (orgs). Coletânea de palestras de convidados nacionais e internacionais. Rio de Janeiro: FPERJ: UsER, 2004.

BINS ELY, V. H. M., DISCHINGER, M., MATTOS, M. L. Sistemas de informação ambiental Elementos Indispensáveis para a Acessibilidade Espacial. Anais do ABERGO, 2002 - VI Congresso Latino-Americano de Ergonomia e XII Congresso Brasileiro de Ergonomia. Recife, 2002.

CARPMAN, J. R. GRANT, M. A. Wayfinding: Abroad view. In R. B. Bechtel \& A. Churchman (Eds.), Handbook of environmental psychology (pp. 427-442). New York: John Wiley, 2002.

DANNA, M. F.; MATOS, M. A. Ensinando Observação: uma introdução. São Paulo: Edicon, 1999. 


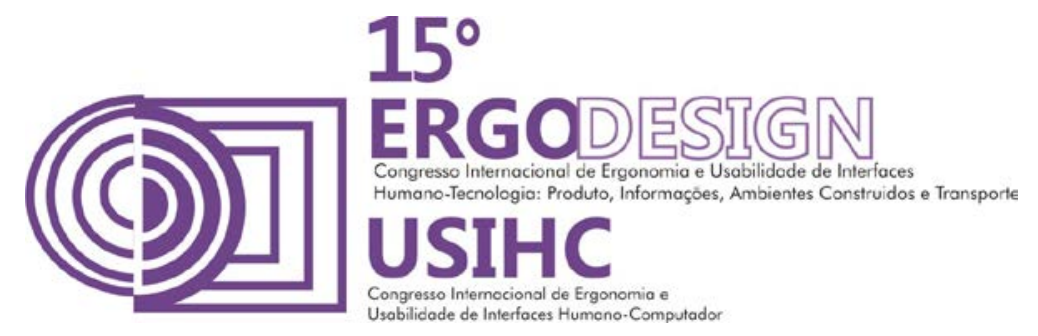

FAGUNDES, Antônio J. F. M. Descrição, definição e registro de comportamento. São Paulo: Edicon, 2006.

LAM, W.H.K., TAM., Wong S.C., WIRESINGLE, S.C. Wayfinding in the passenger terminal of Hong Kong International Airport. Journal of Air Transport Management, 9, 73-81, 2003.

LYNCH, K. A Imagem da cidade. São Paulo: Editora Martins Fontes, 2006

MORAES, Anamaria de. Ergodesign do Ambiente construído e Habitado: Ambientes Urbano, Ambiente Público, Ambiente Laboral.. Rio de Janeiro: Ed. iUsEr, 2004.

MORAES, A.; MONT'ALVÃO, C.. Ergonomia, Conceitos e Aplicações. Rio de Janeiro: iUsEr, 2003.

NIU, L. XU L. TANG Z. Use of gestalt in wayfinding design and analysis of wayfinding process. Frontiers of Architecture and Civil Engeneering in China 2008, vol. 2(4): 386-390.

RANGEL, M. M. Cor e Ergonomia do Ambiente Construído: uma investigação da orientação espacial em um ambiente hospitalar. 255p. Dissertação (mestrado) - Rio de Janeiro: PUC, Departamento de Artes e Design, 2011.

RIBEIRO, L. G. Ergonomia no ambiente construído - um estudo de caso em aeroportos. Dissertação (Mestrado). Rio de Janeiro: PUC, Departamento de Artes e Design, 2004.

Onde estou? Para onde vou? Ergonomia do ambiente construído: wayfinding e aeroportos. Tese (Doutorado em Design). Rio de Janeiro: PUC, Departamento de Artes e Design, 2009.

RIBEIRO, L.; MONT'ALVÃO, C. Habilidades espaciais e estratégias de navegação que influenciam a efetividade do wayfinding. Anais do $7^{0}$ Congresso de Pesquisa \& Desenvolvimento em Design, 2006.

SEBEOK, Th. A. Signs. An introduction to Semiotics. Toronto Buffalo London: University of Toronto Press, 2001.

ZINGALE, Salvatore. Wayfinding using colour: A semiotic research hypothesis. In CHEN, Lin-Lin; DJAJADINIGRAT, Tom; FEIJS, Loe; KYFFIN, Steven; STEFFEN, Dagmar; YOUNG, Bob. Design and semantics of form and movement - DeSForM 2010. Lucerne: 2010. Págs.22-32. 